\title{
A Problem-Analysis-Based Study on the Development Strategy of Small- and Medium-Enterprise Cluster in Shandong Province
}

\author{
Pei Zhang \\ School of Business Management, Shandong University of Finance, Jinan 250014, China \\ E-mail: zhangpei200688@sina.com
}

\begin{abstract}
In recent years, the small- and medium-enterprise cluster has gained fast and healthy development in Shandong province, what contributes a lot to the regional economic development. However, its development still confronts many problems and barriers. Based on a deepening research and analysis on the development of small- and medium-enterprise cluster in Shandong province, this paper puts forward a general strategy and development thought to drive the healthy development of small- and medium-enterprise cluster in Shandong province, according to Shandong's present situation.
\end{abstract}

Keywords: Small- and medium-enterprise cluster, Cluster development strategy, Dislocation development, Innovation culture

Recently, Shandong province has kept on providing with favorable policies in fields of land, taxes, and services, for driving the development of small- and medium-enterprise cluster, aiming at cultivating and developing regional enterprise cluster. Since 1993, Shandong province has taken out 50 million Yuan each year to support the development of enterprise cluster. According to data issued by the small- and medium-enterprise office, there are 121 enterprise clusters whose sales have surpassed 500 million Yuan, including 65,926 enterprises and 3.67 million employees. Therein, there are 90 enterprise clusters whose sales have surpassed 1 billion Yuan, 22 have surpassed 5 billion Yuan, and 9 have surpassed 10 billion Yuan (Qigang Yuan. \& Jinbao Xia, 2006, p117). By developing enterprise clusters, Shandong province has already built up five advantage industrial systems in fields of machine production, textile and apparel, construction materials, chemical, and food processing, what have greatly drive the economic development of Shandong province. In general, the small- and medium- enterprise cluster in Shandong province develops fast. But there are still many problems and barriers in front of its development.

\section{Problems and barriers in the development of small- and medium-enterprise cluster in Shandong province}

\subsection{There are no regional function positioning and general programming for industry arrangement, and industry isomorphism is severe.}

Because there is no rational programming for regional macro arrangement in different regions of Shandong province, enterprise clusters do not possess a clear and reasonable functional position in regional economy. In fact, different regions in Shandong province merely pursue independent industry system instead of establishing and developing their dominant and key industries based on self advantage resources. As a result, the disorder regional functions and the overlapped industries in regions cause the industry isomorphism issue and the blind competition. Take Qingdao, Yantai, Weihai, Jinan, Weifang for examples. Analyze their degrees of isomorphism by similarity coefficient. The similarity coefficient formula is as follow.

$$
S_{i j}=\sum_{i=1}^{n} X_{i k} X_{j k} / \sum_{i=1}^{n} X_{i k}^{2} X_{j k}^{2},\left(0 \leq S_{i j} \leq 1\right)
$$

Here, $S_{i j}$ means the similarity degree of manufacturing between city $\mathrm{i}$ and city j. 0 means completely different. 1 means totally same. $X_{i k}$ and $X_{j k}$ mean the proportions of manufacturing in city $\mathrm{i}$ and city $\mathrm{j}$. The calculation result is in table 1 .

According to the table above, the degree of isomorphism in manufacturing is higher among Jinan, Weifang, Qingdao, Yantai, and Weihai. In fact, concerning with the ten industries, namely automobile, shipping, petrifaction, chemical and rubber, new material, electric information, household electric appliance, textile and apparel, food, and medicine emphasized by Shandong Economy \& Trade Committee, they overlapped mutually in Qingdao, Yantai, Weihai, and Weifang. Take textile and apparel for example. Qingdao and Weifang are almost at a same level. And even Weifang surpasses Qingdao in productivity. In automobile, Qingdao and Yantai are silimar. In shipping, Yantai and Weihai are almost the same. These cities do not make best use of their special advantages. The isomorphism of industrial structure not only influences the stability of clusters, reducing the driving effect of clusters on regional economy, but also hurt the coordinate development of economy because of the jamming effect, exterior diseconomy, and economic cycle brought about by clusters. 
1.2 The lower degree of enterprise aggregation, the lack of specialization and coordination, and the lower cluster equipment ratio.

Comparing with the Yangtze Delta and the Pearl River Delta, the aggregation degree of small- and medium-enterprise cluster in Shandong province is lower in general, being lack of high cluster connecting effect. Some industrial zones occupy large areas but generate lower output. The degree of aggregation is lower. For instance, according to the international development zone's economic intensity evaluation standard, an international development zone should achieve a production of 10 billion Yuan per kilometer. Shanghai development zone realizes 6.8 billion Yuan per kilometer, Zhejiang development zone 2.5-3.5 billion, and Shenzhen high-tech zone 6.45 billion. However, the GDP per kilometer realized in Qingdao development zone is merely 30 percent of that in Suzhou, and the foreign trade in the former is merely 17 percent of that in the later, and the real utility of foreign capitals in the former is only 58 percent of that in the later (Yinghui Sui, 2006). Also, a great number of small- and medium-enterprise clusters aggregate in space, without forming mutually-associated and mutually dependent industry system with specialization and coordination. In one cluster, enterprises do not associate closely in business and technology, being lack of clear industry features. The isomorphism of industry is severe. Besides, there is not a perfect mechanism for the cooperation of enterprises, colleges, scientific and technological research institutions in one cluster. Enterprises do not possess strong ability of scientific and technological research, which makes them fail in continuous development.

The lower equipment of local enterprise clusters is more severe. For example, Qingdao's household appliance industry, the best advantage in Shandong province, has to purchase raw materials, electric parts and components from Eastern China and Southern China (for instance, merely 18 percent of parts and components of air condition are purchased in Qindao). Thereof, only 5 percent of core parts and main electric items are purchased locally. In 2003, Weihai determined to develop three industries, namely shipping equipment, mechanic tools, and electric information, among the five industry clusters. Although they associate closely, the match rate in Weihai is very low. Thereof, the match rate of shipping equipment is merely 3.5 percent, and mechanic tools less than 10 percent, and electric information only 20 percent. Comparing with the Yangtze Delta and the Pearl River Delta, the match rate in Shandong is merely 5 percent or 10 percent of that in the former areas. It influences not only the construction of clusters and industrial function regions, but also the quality of foreign capitals and the transfer of high industries, which makes it hard to exert clusters' advantages in specialization.

\subsection{The enterprise cluster is at its initial stage and its development is lower in general.}

Most small- and medium-enterprise clusters in Shandong province are at their initial stages. Most are labor-intensity clusters, with lower technologies. Enterprises in one cluster stress on competition instead of complement. The stability is low. And these kinds of clusters face relatively greater crowding risks. In the aspect of technology innovation, the transformation of scientific and technological fruits and the technological innovation are poor, being lack of core technology and relevant implementation. And the manufacturing base is at the stage of equipment and construction. The added value is low. It is far from a mature manufacturing base that supports design, research, and development. In Shandong, the augment value of manufacturing is merely 30 percent of that in developed countries, and the labor productivity is only 5 percent or so. Although Shandong has lots of large- and medium- manufacturing enterprises, most are at the producing and processing stages, which are far from ODM (original design manufacturer) and OBM (original brand manufacturer). Because the development of manufacturing does not have an innovation system that fits for global economic competition and drives industrial transformation, manufacturing industry confronts with many problems, such as technological upgrade, increasing costs, and profits allocation, what serve as a series of challenges for small- and medium-enterprise clusters' formation and development.

\subsection{The development of foreign-funded enterprise cluster lags behind, and its localization is poor.}

From the quality of foreign direct investment in Shandong province most are small-scale, low- technology, and labor-intensive. Generally speaking, an investment project with latest technologies and long-term competence demands for relatively large scale of investment. The average of transnational companies' foreign direct investment is about 6 million dollars. In contrast, the number is only 1.4 million dollars. Besides, few enterprise clusters are based on foreign direct investment in Shandong province. Even there is, high-tech projects are few. Up till now, the Samsung Electronics Company has already set up 12 factories, and its investment in Suzhou has reached one hundred million dollars. And among Japan's world top 500 companies, 31 have invested in Suzhou. 11 projects have gained an investment more than one hundred million dollars. This number almost occupies one third of world top 500 companies' total investment in Shandong. Besides, Shandong Peninsula has few foreign-funded high- tech projects. Processing industry has occupies a proportion of 70 percent. Both the added value and the profits from exports are lower. Although some industries are regarded as high-tech industries in statistics, most are just processing factories instead of producing real high-tech products or parts. Moreover, in Shandong province there is a 
"copy cluster chain" phenomena for the foreign-funded enterprise clusters. It is hard for foreign-funded enterprises to amalgamate with local economic and social development. Their localization is poor. For example, most equipped companies for Shandong Samsung Electronics Company already serve the later in Korea. The technologies of local companies can not meet relevant technological requirements. Rongcheng Huatai Automobile has to import key parts from Korea. And 56.2 percent of parts are purchased in China. It just buys parts from Triangle Group in the same city. The match rate is only 2.5 percent in city.

\subsection{The government emphasizes the development of large companies and groups but neglect that of small- and medium- enterprises.}

Shandong economy is featured by "large company, large brand, and large industry". The state-owned large companies have gained well development. But private small- and medium-enterprises do not. Next, let's analyze the fixed assets of different economic subjects in Shandong province in recent ten years from 1996 to 2005 (table 2).

From the figure 1, the proportion of state-owned assets is decreasing annually in Shandong province. Accordingly, the proportion of foreign-funded assets is increasing annually. But the proportion of other economic subjects (chiefly the private economy) does not change a lot, wondering around ten percent. It is well known that the subjects of cluster are chiefly small- and medium- enterprises that belong to private economy. As a great economic province, Shandong does not have well-developed private economy. The effects of small- and medium-enterprises does not gained sufficient emphasis, which makes Shandong province fail to match its position in national economy. The government's supportive policies are not equal, laying more stresses on large companies and groups, neglecting small- and medium-enterprise clusters, emphasizing super large companies and projects, omitting small- and medium-enterprises and projects. As a result, it affects the healthy development of small- and medium-enterprise clusters in Shandong province to a great degree and the general improvement of regional economic quality. It is urgent to encourage private enterprises to realize further development, which will contribute to an industrial cluster and chain development.

\section{The general strategy of driving the development of small- and medium-enterprise cluster in Shandong province}

\subsection{Constitute a general industry programming, and realize clusters' dislocation competition and coordination}

Whether Shandong's small- and medium-enterprise cluster can achieve healthy and long-term development or not is determined by whether the government can constitute a rational programming for industry's general development, realizing the dislocation competition and coordination between regions and clusters, changing the industrial isomorphism and blind competition. Therefore, the initial step is to take the whole province as one great system, comprehensively innovating and perfecting the coordinate system, constitutions, and organizations, forming a general programming for regional development, insisting the principle of economic integration, and achieving the regional integration of economic development. Therefore, it is necessary to deal with the relationship of resources allocation, uses, and exchanges among regions in Shandong province. Use the policy guidance in cluster development and common market to ensure the transfer of industries and the clusters' effective cooperation. In this process, lay stresses on the important effects of integrated rules, services, and networks. Generally program and integrate civil technology standards, research and development resources, industrial arrangement, industrial emphasis, and inviting investments. Make the enterprise clusters in Shandong province possess perfect functions, prominent emphasis, well coordination, and special advantages. Improve the core competence of cluster economy further.

Secondly, cities and counties should exert their comparative advantages and competitive advantages completely according to their regional resources structure, assets structure, and industrial bases, expediting the formation of special cluster advantages over other regions. With "special products, special talents, and special strategies", and the rational choice of social regional center, cities and counties can build up their competition marks and regional brands that meet international standards, speeding up the transformation of people, logistics, capitals, technologies, and information. By developing enterprise clusters and relevant industries, cities and counties can increase the values of cluster assets.

Thirdly, the development of Shandong's small- and medium-enterprise clusters has to follow the principle of comparative interests, strengthening the regional clusters' advantage complement and differentiating cooperation. Realize mutual complement by exchanging regional factors. Exert regional advantages to the largest degree. Make best use of regional resource advantages, industrial advantages, and capital advantages. Therefore, the interest-related subjects in clusters development should focus on the whole regional development, and consider others' interests in development. Based on the regional industry economic cooperation spirit, namely "mutual benefit, complement each other", all interest- related subjects should lay more stresses on sorts of technological 
association, specialization, and coordination. With the support of local governments, they can realize an effective connection of regional advantages and transaction services between regions.

\subsection{Develop small-and medium-enterprises greatly, and increase the clusters'match rate in local area.}

Whether an enterprise cluster can success or not is determined by the head enterprise in the cluster and the coordination of equipped small- and medium-enterprises. Therefore, we should stresses on the cultivation of head enterprises in clusters. Following the principle of government guidance and market operation, support the best and help the power. By augment investment and large projects, cultivate large companies and brands with core competence. Make them exert their heading effects. Meanwhile, clusters are an industrial ecological system. It demands for mutual complement of small- and large- enterprises. Its development is realized in the process of competition and cooperation. Without equipped services from amounts of small- and medium-enterprises, clusters can not exert their advantages. Why lots of Japanese automobile brands achieve success and fast development depends on the support of thousands of equipped small- and medium-enterprises. Therefore, as we cultivate the head enterprise in a cluster, we should emphasize the development of small- and medium-enterprises, encouraging them, especially the energetic private enterprises, to join in the large enterprise' industrial system, forming rational industrial arrangement, driving specialization, achieving a nice circulation of mutual support and cooperation between "the head and the followers", improving regional industries and technologies' competitive advantages, and further expanding the development space of clusters.

To build up a series of equipped resources rapidly is the common way adopted by Tianjin, Suzhou, Kunshan, and Dongguan in order to cultivate large enterprise clusters. In Kunshan, the government sets up a special institution in charge of industrial construction, executing an exterior equipped engineering, and taking out special capitals from finance as encouragement funds and capitals to support the development of equipped enterprises. Presently, it has already cultivated 528 private equipped enterprises, accounting for 90.4 percent of total equipped enterprises. It is possible for Kunshan government to invite all computer parts producers to invest in Kunshan in order to produce a complete computer in Kunshan city. The equipped enterprises greatly decrease the costs of exterior investors, which serve as Kunshan enterprise clusters' largest competitive advantages over other regions. We can take references from these facts. At the same time, it can enhance the localization of foreign-funded clusters.

\subsection{Emphasize on the introduction of foreign capitals, and lay more stresses on developing extroversive enterprise clusters.}

The development of extroversive economy and the introduction of foreign capitals serve as the main driving powers for clusters' fast development. According to the development experiences of southern advanced regions in recent years, the cultivation of one dominant industry has to be guaranteed by two or three projects with more than 50 million dollars per project each year, or one great project with more than 100 million dollars. By this way, it takes three or five years to form a series of extroversive and characterized enterprise clusters. Therefore, we should grasp the strategic chance of world economic structure adjustment, stressing on inviting investments from Japan, Korea, Europe, and America, trying to realize the transformation from project investment toward industrial investment, and the transfer from product-oriented co-funding and cooperation toward cooperative reengineering, purchase and merge, and multi-level transnational strategic cooperation, which can help to gain more technological overflow and knowledge property right. Follow products' added value standard to realize industrial chain investment. Emphasize on the introduction of transnational projects. Make best use of the foreign-funded projects' industrial associative effect, and lay stresses on trace researches on industries and its upward products and downward products. Force equipped enterprises to catch up with the large project. Ensure that the introduction of one large project can form one big industry. In special, build up all kind of favorable conditions and help to set up joint-funded research and development centers. Create a technology-sharing mechanism for foreign-funded enterprises and local enterprises. Drive the upgrade of technologies in local enterprises.

Shandong peninsula city group locates in the seaside of eastern China, neighboring with Japan and Korea over the sea. The distance from Yantai and Weihai to Korea is less than 100 kilometers. Facing with the great chance of economic structure adjustment and industrial transformation in Japan and Korea, Shandong peninsula should make best use of its excellent location, exerting its regional advantages completely. Construct a Japan-Korea "industrial coordination zone" and develop into a production and supply base for Japan and Korea's automobiles, shipping, components of household appliances, parts of large equipments. At the same time, it is necessary to adjust the operation of clusters and enterprises to meet the international rules, guiding clusters and enterprises to produce, process, and sale according to the international standards, speeding up the step of joining in the global manufacturing net and transnational supply chain.

In the process of inviting investment, we should deal with the relationship of clusters' construction and projects' 
short-term interests and long-term interests properly. Evaluate and balance the performances of foreign-funded projects rightly. Emphasize both effects (economic and social effects) and quality (technology, product, and industry structure). Avoid any exaggeration and bubbles in clusters' construction. Meanwhile, the market behavior of foreign capitals in Shandong province should be regulated, managed, directed, and controlled according to international rules and local situations. Clear the irrational benefit policies in local areas completely. Constitute general benefit policies for regional industry. Realize the national treatment for foreign-funded enterprises gradually.

\subsection{Create a better innovative environment and drive the industrial upgrade of clusters.}

The final power that helps to achieve the long-term economic growth in one area is not from natural resources and material capitals, but from scientific and technological progresses and ability of innovation. Therefore, we have to associate the cultivation and development of small- and medium- enterprise clusters with the construction of provincial innovation system, creating an innovation- favorable environment, which can help to improve the ability of research and development, realizing the upgrade of clusters. From the successful enterprise clusters in foreign countries, the government exerts an important effect on the construction of enterprise clusters' innovation environment. And the effect of government serves as a vital condition in determining the success of enterprise clusters.

Firstly, inspire and encourage innovation by supportive policies. The government should make best use of financial policies and taxation policies to encourage clusters and enterprises to keep on making innovation. These policies include financial discount, local tax return, income tax relief and special funds. Meanwhile, the government should support certain locally-characterized innovation projects or some powerful innovative enterprises. Besides, the government should take the lead to achieve the mutual cooperation between financial institutions, medium agencies, colleges, science and research institutions, and enterprises. Constitute relevant policies to encourage enterprise clusters to join in the global industrial value chain system, which can help to improve their abilities of selfinnovation, by learning, assimilating, and absorbing the advanced technologies from transnational companies.

Secondly, construct an overall service system to provide with multi-level services for clusters' innovation. For example, the government can provide with fundamental facilities and public facilities, such as better transportation, communication net, supply of water and electrics, for the development of enterprise clusters. Develop the medium agencies for technological innovation. By building up online technology market and online database for scientific and technological talents, these agencies can provide with information collection and issuance, technology evaluation consultation, technology training service, technology management, and legal services. The government can also organize certain research and development activities and construct a regional innovation platform based on enterprise clusters. Absorb amounts of talents into the platform and improve the innovation ability of clusters and regions. Turn clusters into manufacturing bases supported by design, research, and development.

Besides, emphasize the creation of a better innovative culture and realize the ecological and sustainable development. The government should create a cultural environment that benefits innovation, combining with local features of culture. People in Shandong are hardworking, intelligent, brave, kind, and firm. All these merits contribute to the relatively better development of Shandong's small- and medium-enterprises clusters. However, Shandong people are conservative in general. They are lack of energies in gaining greater success. The spirit of innovation is weak. Therefore, the provincial government in Shandong should encourage the spirit of innovation and the cultural value of confronting risks among people, helping them to accept new things and pursue self values. Besides, the government should cooperate with the media to improve innovative entrepreneurs' political and social positions, creating a better environment for innovation.

\section{References}

Michael Porter. (2002). The Competitive Advantage of Nations. Beijing: Huaxia Publishing House. p263-272.

Sui, Yinghui. (2006). Industry transformation: the industry clusters construction in Shandong peninsula and the strategy. Shandong Economy. No.4. p100-104.

Wang, Rong. (2006). Study on problems in small- and medium-enterprise cluster development and countermeasures. China Economist. No.8. p214-216.

Wei, Houkai. (2006). Improve Chinese enterprise cluster's ability of innovation. Chinese Enterprise Cluster (4). Beijing: China Machine Press. p12-16.

$\mathrm{Xu}$, Yinping. \& Fan, Qiufang. (2006). Study on the problems and countermeasures of Shandong peninsula urban agglomeration. Journal of China University of Petroeum (Edition of Social Science). No.4. p23-27.

Yuan, Qigang. \& Xia, Jinbao. (2006). An analysis of cluster effects in Shandong province and how to avoid negative effects. Shandong Economy. No.6. p117. 
Table 1. The similarity coefficient of manufacturing in Shandong peninsula.

\begin{tabular}{|l|l|l|l|l|l|}
\hline & Jinan & Weifang & Qingdao & Yantai & Weihai \\
\hline Jinan & 1.00 & 0.44 & 0.69 & 0.65 & 0.41 \\
\hline Weifang & 0.44 & 1.00 & 0.48 & 0.82 & 0.76 \\
\hline Qingdao & 0.69 & 0.48 & 1.00 & 0.72 & 0.63 \\
\hline Yantai & 0.63 & 0.82 & 0.72 & 1.00 & 0.78 \\
\hline Weihai & 0.41 & 0.76 & 0.63 & 0.78 & 1.00 \\
\hline
\end{tabular}

Resource: Cities' Statistical Yearbooks in 2004

Table 2. The structure of fixed assets in Shandong province from 1996 to 2005 (\%).

\begin{tabular}{|l|l|l|l|l|}
\hline Year & State-owned & Collectivity-owned & Foreign-funded & Other \\
\hline 1996 & 44.4 & 31.1 & 11.5 & 13.0 \\
\hline 1997 & 43.1 & 31.8 & 11.6 & 13.5 \\
\hline 1998 & 45.6 & 29.7 & 11.4 & 13.3 \\
\hline 1999 & 46.9 & 28.6 & 10.5 & 14.0 \\
\hline 2000 & 45.4 & 26.7 & 14.0 & 13.9 \\
\hline 2001 & 41.2 & 24.5 & 20.6 & 13.7 \\
\hline 2002 & 35.3 & 23.1 & 27.7 & 13.9 \\
\hline 2003 & 30.0 & 22.2 & 33.9 & 13.9 \\
\hline 2004 & 25.1 & 23.2 & 37.9 & 13.8 \\
\hline 2005 & 18.0 & 24.8 & 40.1 & 17.1 \\
\hline
\end{tabular}

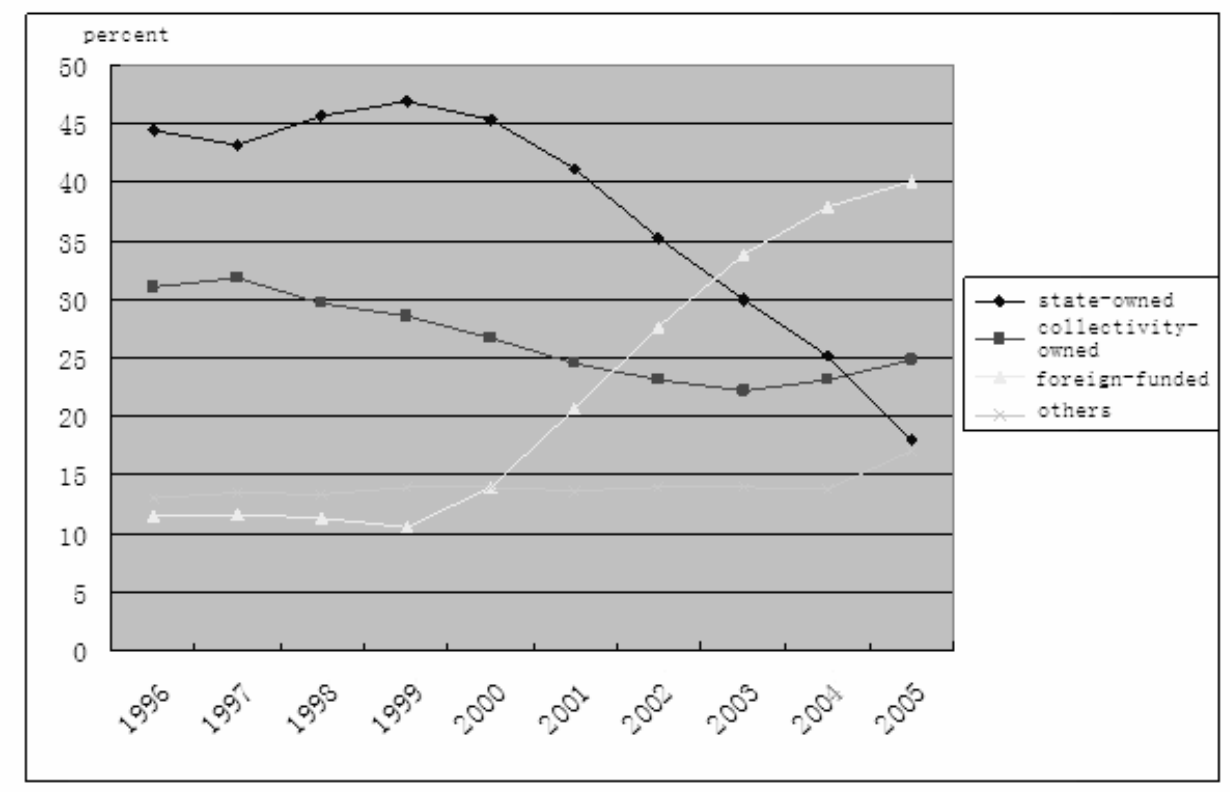

Figure 1.

Resource: Shandong Statistics Yearbook. 